\title{
Enigma in Transformational Leadership - Been There Done That Syndrome vs. Black Box in Transformational Leadership: A Case from Pakistan's Public Sector
}

\section{Hasnain A*}

Institute of Management Sciences, Faculty of Law, Commerce and Business Administration, Bahauddin Zakariya University, Multan, Pakistan

Corresponding author: Hasnain A, Institute of Management Sciences, Faculty of Law, Commerce and Business Administration, Bahauddin Zakariya University, Multan, Pakistan, Tel: +92 61 9210097; E-mail: amna.hasnain@bzu.edu.pk

Received July 28, 2017; Accepted September 20, 2017; Published September 27, 2017

\section{Retraction Note}

The article entitled "Enigma in Transformational Leadership - Been There Done That Syndrome vs. Black Box in Transformational Leadership: A Case from Pakistan's Public Sector," has been accepted for publication in the Business and Economics Journal considering the statements provided in the article as personal opinion of the author which was found not having any conflict or biasness towards anything. As the article was a perspective one, information provided by the author was considered as an opinion to be expressed through publication.

Soon after the publication of the paper, we witnessed some serious concerns and many of them argued that the paper is a personal perspective and had not discussed any relevant ethical issue considered under the journal scope. Moreover, the paper is neither innovative nor thought provoking.

Publisher took decision to make the article online solely based on the reviewers suggestion which considered the article not but a personal opinion of the author. However, it is found that the article has some unavoidable mistakes and issues, therefore, being retracted from the journal. 